\title{
Bozzano and the First Classification of Deathbed Visions: A Historical Note and Translation 1
}

\author{
Ronald K. Siegel \\ Ada E. Hirschman \\ Department of Psychiatry and Biobehavioral Sciences \\ School of Medicine \\ University of California, Los Angeles
}

\begin{abstract}
Ernest Bozzano was an Italian parapsychologist who published, in 1923, one of the most important historical studies on deathbed visions. The book, while influencing such scholars as Charles Richet and Sir William Barrett, remained largely forgotten and untranslated. This paper provides a translation of selections from Bozzano's monograph illustrating his unique classification of deathbed visions.
\end{abstract}

\section{INTRODUCTION}

Recently, a number of studies have attempted to classify the phenomena of near-death experiences, with particular reference to the visions of the dying (e.g., Moody, 1975; Osis \& Haraldsson, 1977; Ring, 1980). Historically, the first such study is generally considered to be William F. Barrett's Death-Bed Visions (1926), while Robert Crookall (1961) was the first to define the major elements of what is now termed the "core" or "prototypic" near-death experience. Barrett himself was heavily influenced by an earlier, albeit forgotten, investigation conducted by Italian Ernesto Bozzano (1923).

Bozzano was born in 1862, and although he is often referred to as Doctor or Professor, he had no formal degrees and was largely selfeducated. He became attracted to parapsychology through the work of Eusapia Palladino during the early 1890s. He wrote numerous monographs on such subjects as mediumship, haunted houses, and ESP. Although his writings cited "data" from academic sources as well as accounts from the spiritualist press, they were well received by lay and professional audiences in Italy and France. In Italy, he was considered the leading psychical researcher among a group that 
included Pictet and Schiaparelli (Reyes, 1970). He had only minimal influence on British and American scholars since his only books to be translated into English were three minor works. Several of his papers appeared in the English edition of a French journal, Annals of Psychical Science, between 1905 and 1910 (Christopher, 1979). The few case studies mentioned in these papers were nonetheless cited by numerous subsequent investigators (Osborn, 1974).

Bozzano contributed regularly to a number of spiritualist publications (e.g., Luce e Ombre, La Revue Metapsychique, and La Revue Spirite) and soon became the chief spokesman for the spiritualist theory that life survived death. The anti-survivalists at the turn of the century were headed by Charles Richet, who was eventually converted to the survival theory by Bozzano. The source of that conversion was a monograph (1923) appearing in French as Phenomenes Psychiques au Moment de la Mort. The date of the original Italian edition is unknown, but references cited in the book include journal articles from 1921. It is important to note that Bozzano's first paper on deathbed visions appeared in the July 1906 issue of Revue du Monde Invisible.

Bozzano sent a copy of this book to Richet, who wrote back that he found Bozzano's discussions and case studies on deathbed visions to be explainable only within the framework of the survival theory. In the opinion of parapsychology scholar D. Scott Rogo (personal communication, 1983), Bozzano's book represents one of the three most important historical studies on deathbed visions, the two others being Barrett (1926) and Hyslop (1918). According to Rogo (personal communication, 1983), "Barrett was greatly influenced by Bozzano, [who] helped him to formulate some of his own views about deathbed visions. In fact, he had annotated his copy of the monograph and was going to write more specifically on Bozzano's views, and his support of them, but died before writing these discussions for his book." Barrett's book, minus these notes on Bozzano, was published posthumously in 1926 .

We have recently obtained a copy of Phenomenes from a rare-book dealer in Paris. The book's 260 pages are divided into three parts: Part I, "Concerning apparitions of the dead at the deathbed" (113 pages); Part II, "Phenomenon of 'telekinesis' in connection with the events of death" (66 pages); Part III, "Transcendental Music" (81 pages). In Part I, Bozzano classifies deathbed visions into six categories of phenomena and cites numerous case examples of each. He considered the first two categories of primary importance and devoted more than half of Part I to a discussion of these cases. The remaining 
categories were given minor attention. Selections from his classification system are given below.

\section{FIRST CATEGORY}

"Cases in which the apparitions of the deceased appear solely to the dying person and relate to persons he knew were dead. [24 cases]

"These are the sorts of manifestations that occur most frequently in the present casuistry; we perceive that they are also the least interesting from a scientific point of view. Given the very vivid state of emotion in which the dying person, who is still conscious, finds himself, and given, also, the hyperaesthesia of the cortical centers, and the more or less morbid conditions in which they are functioning; and, finally, given the inevitable bent of thought of the dying person who can only turn with supreme agony toward the dear and withdrawn ones, and toward those who have preceded him to the grave, one can easily conceive that all this frequently determines the phenomena of subjective hallucination.

"Despite this, scientific research methods require us to note that in the cases of apparitions of the dead appearing at the deathbed, we meet a circumstance that cannot be easily explained by the hallucinatory hypothesis; and that is that if the thoughts ardently turned to loved ones were the determining cause of the phenomena in question, the dying person rather than submit solely to hallucinations about the deceased - sometimes deceased forgotten by the patient - should more frequently still be the subject of hallucinations portending to living persons to whom he is closely attached - which does not happen" (pp. 4-5).

\section{SECOND CATEGORY}

"Cases in which the apparitions of the deceased are still perceived only by the dying person, but refer to persons whom he did not know were dead. [ 6 cases]

"The instances belonging to this category are divided into two distinct classes. The first concerns cases in which the attendants had knowledge of the death of the person who will be subjectively appearing to the patient who is ignorant of the fact of the death; the second refers to cases in which the patient and the attendants are equally unaware of the fact in question. In both circumstances one 
arrives again at explaining the facts by the hallucinatory hypothesis combined with telepathy. In the first instance, it suffices to assume a phenomenon of unconscious telepathic transmission on the part of the attendants; in the second, one must have recourse to telepathic transmission at a distance" (p. 42).

\section{THIRD CATEGORY}

"Cases in which other people gathered about the dying person perceive the same phantoms that he does. [ 8 cases]

"This group of cases, with a collective perception of the same phantom, presents a great deal of theoretical interest, where one arrives once again at the hypothesis of telepathic transmission of thought although one does not find oneself facing any special circumstances. In effect, the coincidence of the apparition viewed by third persons, collectively with the dying one, can be attributed to the fact that the latter serves as the transmitting agent of an elaborate form of hallucination in the brain, and that is in the case of simultanecus visualization; if, on the other hand, the phantom is seen by the attendants and the dying person at different times and places, then that fact acquires a great theoretical significance in the sense of spiritualistic interpretation" (p. 53).

\section{FOURTH CATEGORY}

"Cases of apparitions at the deathbed coinciding with predictions or similar confirmations obtained by means of mediums. [7 cases]

"In this case, one can always suppose that an apparition at the deathbed, predicted or affirmed by a medium, takes root in a telepathic rapport being produced between the subconscious of the medium and that of the patient, or between that of the medium and the patient, the medium and the physicians" (p. 70).

\section{FIFTH CATEGORY}

"Cases in which the intimates of the dying person are the only ones to see the phantoms of the dead. [ 9 cases]

"Cases of this nature are pretty rare, and that is natural as, in the order of probabilities, we are aware that most manifestations appear 
to the dying persons alone, and that apparitions appearing to the patient and the attendants together are relatively rare and rarer still are those perceived by the attendants alone.

"Concerning the theoretical interpretation of these facts and from an absolutely scientific point of view, they are liable to be explained by telepathic hypothesis, supposing a phenomenon of transmission of thought from the dying person - under special circumstances" (pp. 85-86).

\section{SIXTH CATEGORY}

"Examples of apparitions of the dead, appearing a short time after a death and observed in the same house where the corpse lies. [1 case]

"Everyone can readily understand the great theoretical importance of the cases which now concern us. If one could collect a sufficient number of examples, they would make an important contribution in favor of the spiritualist thesis. That possibility is, however, still remote; the facts in question are the rarest ones, which is not surprising, given the extraordinary conditions which are necessary to produce them" (pp. 102-104).

\section{CONCLUSIONS}

"With this work on the phenomena 'of apparitions of the deceased at the deathbed,' I have applied myself to a hard task, and the conclusions to which I have arrived can be summarized in the following terms:

"According to the methods of analysis compared between the telepathic phenomena and the 'visions of the dying,' it appears to indicate that when these visions are perceived solely by the attendants, or else by the attendants and the dying person, one must exclude in principle that the event is produced through telepathic communication from the thoughts of the dying person. It therefore follows logically that the visions perceived solely by the dying person cannot have a different origin from the others, and that, consequently - always as a general rule - the same source must be attributed to the entire group of phenomena. As to the nature of this source, one can argue the case of collective visions, or the identity of a phantom that cannot be explained by transmission of hallucinatory thoughts of the dying one returning by necessity the worth of the proof. It is what also proves the kinds of phenomenal manifestations too often irrecon- 
cilable with the hallucinatory hypothesis. In other words: according to the scientific study of the manifestations in question, one is brought to the conclusion that the hallucinatory and telepathichallucinatory hypotheses are insufficient to explain all the facts, and that, by contrast, the spiritualist hypothesis lends itself to this most admirably" (pp. 112-113).

\section{COMMENT}

Prior to Bozzano's classification scheme, investigators of psychic phenomena had published numerous cases of apparitions occurring at death, but none had concentrated on the deathbed visions per se. And none had attempted to group these seemingly complex and idiosyncratic phenomena into cohesive and well-defined categories. Bozzano accomplished all of that. And while his interpretations were heavily influenced by spiritualist and psychic thinking, he entertained alternative explanations such as the hallucination hypothesis.

In the beginning of the book, Bozzano remarked that he was not trying to prove a thesis but to recall a number of incidents that had a limited scientific value but, when taken together, had a greater value. The collective value of the cases convinced Bozzano, Richet, and others that the survival theory was the most salient explanation for deathbed visions. Bozzano's arguments may be far from compelling, but we can be pleased that the soul of his work, if not his body, has survived.

\section{NOTE}

1. The authors thank D. Scott Rogo for supplying helpful information on the life and works of Ernest Bozzano.

\section{REFERENCES}

Barrett, W.F. Death-Bed Visions. London: Methuen, 1926.

Bozzano, E. Phenomenes Psychiques au Moment de la Mort. Paris:

Editions de la B.P.S., 1923.

Christopher, M. Search for the Soul. New York: Crowell, 1979. Crookall, R. The Supreme Adventure. London: James Clarke, 1961. Hyslop, J.H. Visions of the dying. Journal of the American Society for Psychical Research, 1918, 12, 585-646.

Moody, R. Life After Life. Covington, Ga: Mockingbird, 1975. Osborn, A.W. The Supernatural. New York: Harper \& Row, 1974.

(originally published 1937) 
Osis, K., and Haraldsson, E. At the Hour of Death. New York: Avon, 1977.

Reyes, B.F. Scientific Evidence of the Existence of the Soul. Wheaton, Ill.: The Theosophical Publishing House, 1970. (originally published 1949)

Ring, K. Life at Death. New York: Coward, McCann and Geoghegan, 1980.

Requests for reprints to:

R.K. Siegel, Ph.D.

P.O.B. 84358

VA Branch

Los Angeles, California 90073 